\title{
SUPPORTING FILE
}

\section{THE EFFECT OF COMPOSITION AND INTERFACIAL TENSION ON THE RHEOLOGY AND MORPHOLOGY OF HEAVY OIL-IN-WATER EMULSIONS}

Marianna P. Arinina, * Kirill V. Zuev, Valery G. Kulichikhin, and Alexander Ya. Malkin

A.V. Topchiev Institute of Petrochemical Synthesis, Russian Academy of Sciences,

29 Leninsky prospekt, 119991 Moscow, Russia.

* corresponding author, e-mail: arinina.marianna@ips.ac.ru.

Table S1. SARA-analysis of the Yarega heavy crude oil

\begin{tabular}{lcc}
\hline Group of compounds & Content, wt. $\%$ & Total value, wt. $\%$ \\
\hline Paraffins + Naphthenes & 36.7 & 36.7 \\
\hline Light aromatics & 9.3 & \\
Medium weight aromatics & 7.5 & 39.7 \\
Heavy aromatics & 22.9 & \\
\hline Neutral resins & 7.6 & 20.8 \\
Acidic resins & 13.2 & 2.9 \\
\hline Asphaltenes & 2.9 & \\
\hline
\end{tabular}

Table S2. GC-MS results for the Yarega heavy crude oil (The composition of the fractions boiling under $270{ }^{\circ} \mathrm{C}$ )

\begin{tabular}{lc} 
Group of compounds & Content, wt. \% \\
\hline Paraffins & 11.09 \\
\hline Naphthenes & \\
\hline mono- & 10.51 \\
bi- & 27.91 \\
tri- & 18.82 \\
tetra- & 15.49 \\
penta- & 3.59 \\
hexa- & 0.00 \\
\hline Aromatics & 12.60 \\
\hline
\end{tabular}



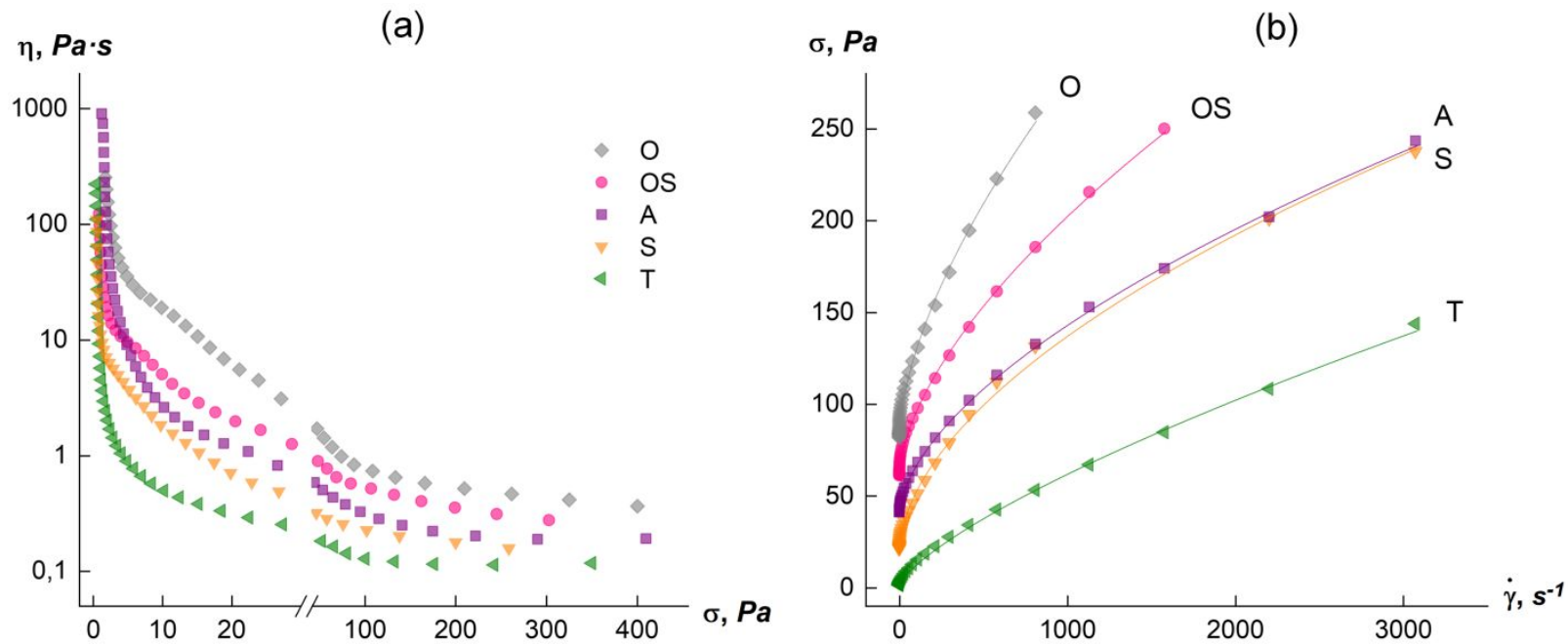

Figure S1. (a) Viscosity curves for the S2 emulsions at $20^{\circ} \mathrm{C}$. (b) Flow curves for S2 samples at $40{ }^{\circ} \mathrm{C}$ drawn according to the Hershel-Bulkley equation (for visual clarity all curves except $T$, are shifted by 20 units along the Y-axis). 
Table S3. Main characteristics of the surfactants and polymer viscosity enhancer used

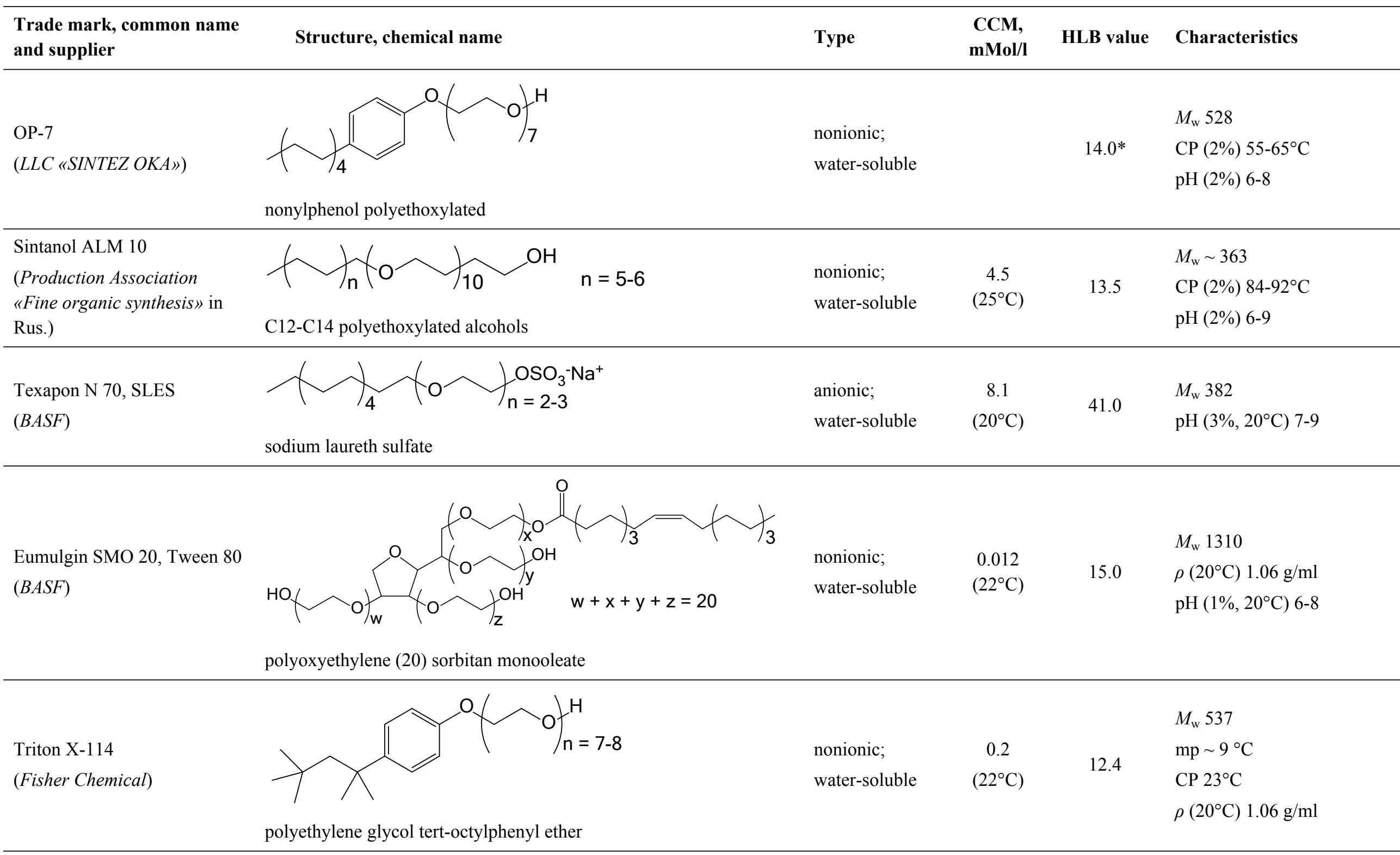




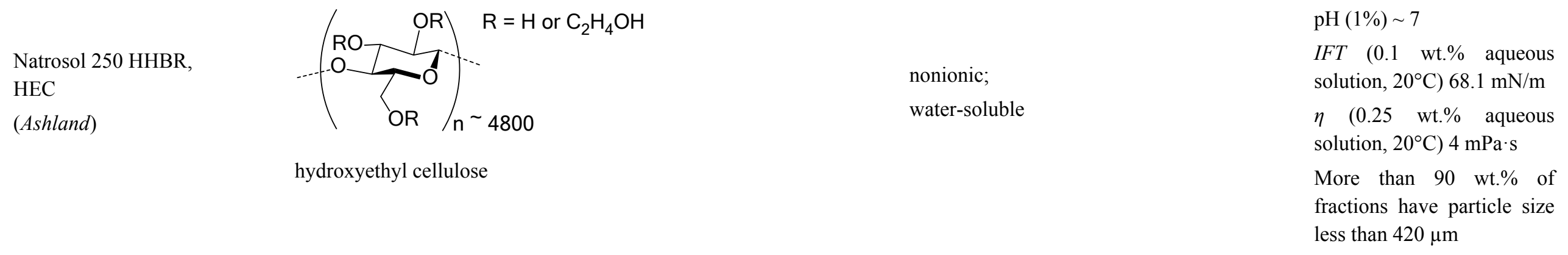

\section{Abbreviations and designations used in Table S2:}

$\mathrm{CCM}$ - critical concentration of micelle forming;

$M_{\mathrm{w}}$ - average molar weight $(\mathrm{g} / \mathrm{mol})$;

$\mathrm{mp}$ - melting point;

$\mathrm{CP}$ - cloud point of the solution;

$\rho$ - density of the solution;

HLB - hydrophilic-lipophilic balance value for solution of surfactant;

$\eta$ - viscosity.

* calculated HLB values based on Griffin theory for ethoxylated surfactants or Davies method for others

$M_{\mathrm{w}} \sim 1.0 \cdot 10^{0}$

$\rho\left(2 \%, 20^{\circ} \mathrm{C}\right) 1.0 \mathrm{~g} / \mathrm{ml}$

$\mathrm{H}(1 \%) \sim 7$

solution, $\left.20^{\circ} \mathrm{C}\right) 68.1 \mathrm{mN} / \mathrm{m}$

$\eta \quad(0.25 \quad$ wt. $\%$ aqueous

More than 90 wt.\% of

less than $420 \mu \mathrm{m}$ 